\title{
Formação inicial do professor de matemática para escolas do Campo: 'olhares' da comunidade campesina
}

\section{Initial education of math teacher for rural schools: 'looks' of the peasant community}

\author{
Wagner Auarek \\ wagnerauarek@gmail.com \\ Floriano Viseu \\ fviseu@ie.uminho.pt
}

\begin{abstract}
Resumo
Estudos no campo da formação de professores apontam a reflexão como uma estratégia para lidar com a complexidade e a diversidade de situações que abarcam a ação docente. Trata-se de formar um profissional que seja capaz de desenvolver a prática docente em consonância com as demandas e a realidade do contexto social e cultural onde acontece a docência. Neste sentido, as Licenciaturas de Educação do Campo da Universidade Federal de Minas Gerais tem a sua estrutura curricular organizada em espaços e tempos de formação em regime de alternância. A proposta da formação por alternância suscita a imersão do licenciando na realidade das comunidades campesinas e de suas escolas com a intenção de percebê-la como espaço privilegiado e legítimo da sua ação de 'ser' e 'estar' como professor. Na execução do Trabalho de Conclusão de Curso (TCC), o licenciando realiza um estudo e elabora uma proposta pedagógica sobre questões da comunidade em que se insere. Tendo como referência o TCC, procuramos identificar as percepções de duas licenciandas sobre os saberes produzidos na comunidade campesina na busca de explicação e significado de fenômenos que contatam no dia a dia. Adotando uma metodologia qualitativa e interpretativa, procuramos indicadores que ajudem a compreender novos 'olhares' sobre o cotidiano da comunidade. Esses 'novos' olhares mostram-se fundamentais na construção do perfil desses atores que serão os futuros professores de matemática nas escolas do campo e que podem levar a escola a ocupar um espaço político e propositivo na vida da comunidade. Este estudo aponta a necessidade de se avançar com a materialização do papel da escola campesina na prática docente.
\end{abstract}

Palavras Chave: Formação de professores; Educação do campo; Educação matemática.

\begin{abstract}
Studies in the field of teacher education identify reflection as a strategy to deal with the complexity and diversity of situations that include the teaching activity. It is about training a professional who is able to develop the teaching practice in line with the demands and reality of the social and cultural context where teaching takes place. In this sense, the Field Education Degrees of the Federal University of Minas Gerais have their curricular structure organized in spaces and times of training in an alternation regime. The proposal of this alternation training raises the immersion of the trainee in the reality of the peasant communities and their schools with the intention of perceiving it as a privileged and legitimate space of their action of being and behaving as a teacher. In the execution of the Course Completion Work (TCC), the trainee performs a study and elaborates a pedagogical proposal on issues raised on the community in which he is inserted. With reference to TCC, we try to identify the two graduates' perceptions about the knowledge produced in the peasant community in search of explanation and meaning of phenomena that they contact daily. Adopting a qualitative and interpretative methodology, we look for indicators that help us to understand new 'looks' about the daily life of the community. These 'new' perspectives are fundamental in building the profile of these actors who will be the future teachers of mathematics in the rural schools and who can lead the school to occupy a political and purposeful space in the life of the community. This study highlights the need to move forward with the materialization of the peasant school role in teaching practice.
\end{abstract}

Keywords: Teacher education; Field education; Mathematics education. 


\section{Introdução}

Ao longo das últimas décadas tem-se solidificado a área de estudos sobre a formação do professor, entre os quais se destacam os que se debruçam sobre a formação para a docência no/do Campo. Esse estudos são consensuais em indicar que a formação de professores para as escolas do campo alicerçada no paradigma da racionalidade técnica, modelo arquitetado na concepção positivista do conhecimento, não dá conta dessa demanda. Atualmente, defende-se um modelo formativo para a Educação do Campo que contemple o desenvolvimento do pensamento reflexivo e crítico, que, como sugere Freire (2011), promova a curiosidade ingênua em curiosidade perspicaz e crítica diante dos problemas da prática docente e da realidade em que essa prática é desenvolvida na intenção de entender e captar ao máximo a sua complexidade. Em conformidade com essa perspectiva de formar um professor reflexivo, com identidade sobre as questões do Campo e atento às demandas do universo campesino, o curso de Licenciatura do Campo - LeCampo da Universidade Federal de Minas Gerais/UFMG propõe e organiza o seu currículo por área de conhecimento, com espaços e tempos de formação que acontecem em regime de alternância. Essa proposta põe em relevo a relação teoria e prática como justapostas, entendendo a ação docente e a prática educativa como alimentadoras da formação do educador do campo em seus conhecimentos, saberes e identidade. Ao longo do curso, tal proposta oportuniza aos licenciandos manterem contato com os múltiplos contextos do espaço de vida e do trabalho no campo. Nessa intenção, o planejamento e a execução do Trabalho de Conclusão de Curso (TCC) inserem-se como um momento da formação inicial do professor que possibilita o exercício da construção de saberes e conhecimentos sobre a docência e a realidade das escolas do campo. Esse contato reflexivo e crítico em relação à realidade vai ter sentido na formação do licenciando se apontar um norte para ações futuras e contribuir para a sua identificação, como Educador, com as lutas campesinas.

Tendo em consideração tais pressupsotos, o objetivo deste estudo consiste em identificar as percepções de duas licenciandas sobre os saberes produzidos na comunidade campesina na busca de explicação e significado para os fenômenos que contactam no dia-adia. Na concretização deste objetivo efetuamos uma reflexão sobre a proposta de formação de Educador do Campo, com foco na área de conhecimento da matemática, desenvolvida pela Licenciatura em Educação do Campo - LeCampo. Essa reflexão ocorre a partir da leitura dos textos construídos por duas licenciandas em seus Trabalhos de Conclusão de Curso (TCC). Esses textos trazem depoimentos sobre a experiência que realizaram em pesquisa focada na 
cultura e nos saberes matemáticos e não matemáticos presentes na comunidade. Nessa intenção, apresentamos primeiramente uma contextualização da Educação do/no Campo.

Em seguida, articulamos um diálogo entre as diretrizes de formação do professor para as escolas do campo e as propostas de formação inicial de professores para os vários espaços educativos, tendo como suporte teórico Schön, Nóvoa, Garcia, Arroyo, Paulo Freire, Molina, entre outros. Em continuidade, trazemos discussões e concepções sobre a formação inicial do professor de matemática e a proposta de formação desses professores para as escolas no/do campo, emergindo a discussão do lugar da prática, o contato ativo e participativo com o contexto real onde a ação educativa acontece durante a formação inicial. Finalizamos com trechos de relatos das licenciandas em seus TCCs sobre a sua imersão na realidade campesina. $\mathrm{Na}$ análise dos dados focamos a nossa atenção nos indicativos referentes ao desenvolvimento de um perfil de educador, além da importância de uma formação focada na identidade de professores de Matemática de escolas campesinas.

\section{Contextualizando a educação do campo}

A Educação do Campo no Brasil completou 20 anos de trajetória em 2016. Trata-se de uma trajetória de conquistas históricas e de constantes desafios. Em seu estudo, Molina (2011) traz reflexões sobre a trajetória do Movimento da Educação do Campo ao esclarecer que as mobilizações dos movimentos sociais e sindicais ligados ao campo

organizaram-se e desencadearam um processo nacional de luta pela garantia de seus direitos, articulando as exigências do direito à terra com as lutas pelo direito à educação. Esse processo nacionalmente se reconhece como Movimento de Educação do Campo. Sua novidade se refere principalmente ao protagonismo de sujeitos que não haviam antes ocupado a cena educacional brasileira: os trabalhadores rurais. É em função desse protagonismo que o conceito Educação do Campo se vincula necessariamente ao contexto no qual se desenvolvem os processos educativos e os graves conflitos que ocorrem no meio rural brasileiro, em decorrência dos diferentes interesses econômicos e sociais em disputa pela utilização desse território. (MOLINA, 2011, p. 18)

Nesse contexto de luta, é certo o entendimento da dificuldade de se explicitar uma denominação específica e acabada para a Educação do Campo, pois essa se constitui um processo histórico e, portanto, em contínua construção. Ainda sobre a Educação do Campo como um processo histórico e emancipador, Fernandes (2006) considera que ela surge.

da combinação das lutas dos sem-terra pela implantação de escolas públicas nas áreas de reforma agrária com as lutas de resistência de inúmeras organizações e comunidades camponesas para não perder suas escolas, suas experiências de educação, suas comunidades, seu território, sua identidade. (p. 28) 
A promulgação, em 2002, das Diretrizes Operacionais para a Educação Básica do Campo - CNE/CEB $n^{\circ}$ 1. 3/04/02, elaboradas a partir de propostas dos movimentos sociais e aprovadas pelo Conselho Nacional de Educação representou uma grande conquista para a educação dos povos do Campo. O documento do Texto Base da II Conferência Nacional por uma Educação do Campo define propostas para a educação nas Escolas do Campo e elementos que levam a uma definição curricular além de se referenciarem na condução pedagógica do processo pelos educadores, com a participação efetiva dos educandos, vistos também como sujeitos coletivos, vinculados a processos sociais, políticos e culturais. Esse contexto favoreceu o surgimento, em várias universidades do Brasil, dos cursos específicos para formar docentes para atuar em diversos coletivos sociais, étnicos, raciais, geracionais e do Campo (ARROYO, 2008). Entre as universidades que aceitam o desafio da Educação do Campo e se tornam parceiras nessa luta pela formação de professores do campo encontra-se a Universidade Federal de Minas Gerais -UFMG/Brasil, que consolida a Licenciatura em Educação do Campo-LeCampo como um curso regular na instituição em 2009 propondo a metodologia de alternância como condutora de sua organização formativa, de maneira tal que o licenciando alterne as suas atividades entre: (1) o Tempo Escola (TE) - tempo de formação na Faculdade de Educação -UFMG); e (2) o Tempo Comunidade (TC) - tempo para refletir e planejar atividades pedagógicas a partir da prática social junto da comunidade rural em consonância com os conhecimentos e teorias relativos à área de formação, estudados no Tempo Escola (TE).

A Pedagogia da Alternância do LECampo/FaE/UFMG propicia ao licenciando manter uma reflexão continuada sobre as práticas sociais que vive no Tempo Comunidade. Na concretização destas atividades manifesta-se o potencial inovador da dinâmica da Pedagogia em Alternância no sentido da solução de problemáticas conjunturais do Campo: elementos de debate e reflexão socializados no Tempo Escola.

As Diretrizes Operacionais para a Educação Básica do Campo sinaliza ser fundamental considerar as especificidades das populações e das condições de vida campesinas nas Escolas, implicando que a formação inicial dos professores considere a formação pedagógica e das áreas do conhecimento de acordo com a Educação do Campo, numa formação para além do espaço escolar de maneira que a experiência e o contato com as questões reais se assumam como um lugar de aprendizagem, produção de saberes e de caráter formativo e identitário da docência do campo. 


\section{A formação inicial de professores na Educação do Campo}

Em seu estudo, García (1999) define o ato de ensinar como profissão, apresentando três fases do processo formativo do professor: a formação inicial; a formação durante a realização do estágio; e a formação no desenvolvimento profissional dos professores. Nos últimos anos, as pesquisas e as políticas públicas direcionadas à formação de professores têm reconhecido e dado relevância à Formação Inicial na e para a qualificação da educação escolar. Esse reconhecimento da formação inicial tem como motivos os desafios que o professor recémformado, ou mesmo os licenciandos, encontram ao lidar com a prática docente e a diversidade de contextos sociais e culturais onde essa prática acontece. Esses condicionantes da realidade escolar demandam novos saberes e compromissos à prática dos professores, bem como na/para a sua ação docente. Fanfani (2007) nos esclarece que

existe uma série de mudanças sociais que, junto com as transformações ocorridas nos sistemas educativos, interpelam o trabalho de professores da educação básica. Essas transformações constituem o pano de fundo sobre o qual se desenvolve a luta pela renovação da identidade docente. (p. 336)

A formação inicial de professores é um espaço privilegiado ao se proporcionar conhecimentos essenciais à profissão docente. Porém autores como Arroyo (2007, 2008), Fanfani (2007) tecem críticas à incongruência e fragilidade dessa formação, que não dá conta de preparar os professores para as novas configurações do espaço escolar e da diversidade cultural, social e econômica que compõem o perfil dos sujeitos presentes nas salas de aula. Segundo Fanfani (2007), o paradigma escolar tradicional não confere sentido à experiência escolar e à ação docente, não servindo aos alunos nem aos docentes, por se distanciar do que demanda a configuração atual da sociedade. Justifica-se a busca de novas propostas e concepções de formação de professores que estejam congruentes com as novas tarefas da educação pois

especialmente para pensar novas formas de entender os novos sujeitos, com as suas diferenças e particularidades, para que tenham aprendizagens significativas. (...) Os professores precisam adquirir conhecimentos teóricos sobre a educação e seus fundamentos, articulando os saberes com as experiências, de modo a se posicionarem no contexto da ação, em sua história formativa. (LOPES, 2016, p. 2)

Na procura de definir a formação dos professores para os tempos atuais, Viseu (2009) salienta que a formação inicial de professores segue diferentes tendências e perspectivas que determinam as finalidades e intencionalidades do processo educativo, o papel da escola e as competências do professor. Centramos nossa explanação em duas dessas tendências que vêm sendo amplamente discutidas e estudadas e que apresentam posicionamentos 
reconhecidamente divergentes. A primeira é a concepção considerada de caráter tecnicista ou, como a define Schön (1987), o modelo da racionalidade técnica, vendo nela um componente da crise das profissões na contemporaneidade. Segundo Viseu (2009), esse modelo apresenta sérias limitações, pois "não toma em consideração o caráter problemático, incerto, valorativo e único das situações profissionais, assentando numa visão tecnicista do professor, na autoridade do conhecimento académico e na desvalorização da prática” (p. 81).

A outra tendência é a concepção considerada de caráter reflexivo. O termo 'profissional reflexivo' foi desenvolvido por Schön (1983) a partir de trabalho de Dewey com a finalidade de definir um modelo de profissional capaz de refletir sobre a ação e a partir dela criar estratégias para lidar com as problematizações do seu cotidiano de trabalho. O perfil do professor reflexivo é descrito por Alarcão (1996) como o profissional que se conscientiza de quem é, das razões pelas quais atua, do lugar que ocupa na sociedade e que se assuma como "agente ativo do seu próprio desenvolvimento e do funcionamento das escolas como organização ao serviço do grande projeto social que é a formação dos educandos” (p. 177). A integração da criticidade neste processo é vista por Zeichner (1993) como uma capacidade do professor de valorizar aspectos da escola e da comunidade como espaços de referência da prática e não estar somente circunscrita à sala de aula.

Ao estudar as estratégias de formação, de natureza reflexiva, Amaral, Moreira e Ribeiro (1996) descrevem situações que essas estratégias acarretam. Entre elas destacamos a que se centra nos aspectos éticos, sociais e políticos de âmbito geral, o que deve levar o formando desde o início de sua trajetória formativa a tomar consciência da dimensão dos diferentes interesses sociais e institucionais que implicam o seu trabalho docente. Considerando o Educador do Campo, é importante, como indica Pimenta (2005), o desenvolvimento dos saberes da experiência que advém das ações desenvolvidas no cotidiano. A respeito dos saberes e do conhecimentos necessários à formação inicial de professores para a especificidade da educação do campo, Molina (2011) destaca a abrangência dessa formação crítica e reflexiva ao afirmar que o

$$
\begin{aligned}
& \text { educador do campo precisa de uma formação que o habilite a refletir sobre } \\
& \text { sua experiência, comprometido com a luta, que considera o modo de } \\
& \text { produção da vida com o trabalho com a terra, com a água e com as plantas } \\
& \text { como digno e bom. O educador do campo precisa ter a compreensão da } \\
& \text { dimensão do seu papel na construção de alternativas de organização do } \\
& \text { trabalho escolar. (p. 118) }
\end{aligned}
$$

Dialogando com as ideias de Freire (1981), a reflexão é o movimento efetivado entre o fazer e o pensar e vice-versa. A ação se fará autêntica práxis se o saber dela resultante se fizer 
objeto da reflexão crítica e transformadora, numa leitura da realidade e da relação dessa realidade com a prática. Nesse sentido, Auarek e Souza (2017) entendem que formar para a educação de campo

não é apenas formar um professor com um olhar genérico para as múltiplas questões, demandas e realidades do e no campo. Em nosso entendimento, é formar um professor com um olhar refinado, reflexivo e crítico em relação às necessidades reais do mundo campesino do qual faz parte, em relação à realidade próxima, vivida na sua localidade, e essa em relação às complexas configurações do nosso tempo. (p. 387)

\section{A formação do professor de matemática no Lecampo}

No campo das pesquisas sobre a formação inicial temos vários estudos que se debruçam especificamente sobre o professor de matemática, que trazem discussões e reflexões sobre 'o que é', 'para quê' e 'como' formar professores de matemática. Essas discussões e reflexões nos apresentam concepções que buscam definir saberes e conhecimentos necessários à formação inicial do docente em matemática, que, como ressalta Ponte (1994), deve ser necessariamente diferente de um curso de matemática que visa formar matemáticos para se dedicarem prioritariamente à pesquisa e ao bacharelado.

Corroborando com elementos para o entendimento da especificidade da formação do professor de matemática, Fiorentini (2005) ressalta que "o conhecimento do professor de Matemática deve estar relacionado com os contextos e situações em que ele irá utilizar tal conhecimento, isto é, com atividades, objetivos educacionais e contextos de ensino da matemática” (p. 71) e que "a Matemática em ação do educador matemático está, sempre, situada em uma prática social concreta, na qual ganha sentido e forma/conteúdo próprios, sendo reconhecida e validada no/pelo trabalho" (FIORENTINI \& OLIVEIRA, 2013, p. 92). Discorrendo sobre o que considera competências necessárias a serem desenvolvidas na formação, Ponte (1994) denomina a

a formação pessoal, social e cultural dos futuros docentes (...) é, muitas vezes, completamente ignorada. Parte-se do princípio que todo o estudante universitário teve oportunidade, pela sua formação escolar e não escolar anterior, de se desenvolver como pessoa e como cidadão o suficiente para poder vir a ser um bom professor, mas, na verdade, isso nem sempre acontece. A formação nestes campos pode favorecer o desenvolvimento de capacidades de reflexão. (p. 2)

Nesse rumo, o LeCampo tem como proposta levar os licenciandos a compreenderem a possibilidade do ensino da Matemática que atenda às especificidades e a diversidade de realidades e demandas campesinas sinalizando a importância dos professores incorporarem a 
cultura e os saberes dos alunos e da comunidade na qual se insere a Escola em suas práticas pedagógicas. Em consonância, estudos etnomatemáticos defendem que é necessário fazer do ensino da matemática,

algo vivo, lidando com situações reais no tempo [agora] e no espaço [aqui]. E através da critica, questionar o aqui e o agora. Ao fazer isso, mergulharmos nas raízes culturais e praticarmos dinâmica cultural. Estamos, efetivamente, reconhecendo na educação a importância das várias culturas. (D’AMBROSIO, 2005, p. 46)

Consideramos fundamental a inserção dos saberes considerados populares ou do universo campesino no processo formativo do professor do campo, sem entender como uma simplificação do ensino da Matemática. Esta preocupação é destacada por Knijnik (2001) ao discorrer sobre

a importância de dar visibilidade, no currículo escolar, a estes saberes usualmente silenciados - o que chamo de Matemática Popular -, colocandoos em interlocução com os saberes científicos, isto é, o que comumente chamamos de Matemática, saliento que é preciso estarmos bastante atentos para não glorificarmos nem os saberes populares, tampouco os acadêmicos, o que implica problematizá-los, analisando as relações de poder envolvidas no uso destes diferentes saberes. (p. 26)

Concordamos com D’Ambrósio (1990) quando considera que uma postura Etnomatemática na realização da prática educativa do professor é almejar que essa vá além do ensinar, vivenciando o universo sociocultural do aluno, reconhecendo, valorizando e redimensionando aspectos dessa realidade, além de desenvolver uma postura reflexiva e crítica sobre as várias possibilidades de construções e relações de poder e de intenções que permeiam a produção do conhecimento matemático, principalmente no universo campesino.

A prática educativa e o contato com a diversidade da realidade campesina e das escolas do campo é um componente presente na proposta de superação das concepções homogeneizadoras de formação no sentido da construção de uma identidade profissional do professor do campo (Molina, 2009). Significando que esses professor do campo assuma que a “profissão docente é uma prática social, ou seja, como tantas outras, é uma forma de se intervir na realidade social, no caso, por meio da educação que ocorre, não só, mas essencialmente nas instituições de ensino" (PIMENTA \& LIMA, 2006, p. 6). Para tanto, a proposta do curso é que a prática deve estar presente desde o início do curso e permear todo o processo formativo. Essa proposta está vinculada à denominada Formação Integradora, que compreende as atividades desenvolvidas nas disciplinas como a Prática de Ensino, Estágio supervisionado, bem como nas atividades articuladas nos Seminários Temáticos: Trabalhos de 
Campo e Grupo de trabalho e na proposta e desenvolvimento de estudo e pesquisa realizadas no Trabalho de Conclusão de Curso.

\section{Metodologia}

Atendendo à natureza do objetivo deste estudo, que consiste em identificar as percepções de duas licenciandas sobre os saberes produzidos na comunidade campesina na busca de explicação e significado de fenômenos que contatam no dia a dia. Tais percepções permitem apresentar uma reflexão sobre a proposta de formação do Educador do Campo. Na concretização do objetivo delineado, adotamos uma abordagem qualitativa e interpretativa na procura de compreender o significado que as licenciandas dão à cultura e aos saberes matemáticos presentes nas comunidades campesinas (ANDRÉ \& AFONSO, 2000). Os dados apresentados derivam dos Trabalhos de Conclusão de Curso (TCC) de duas formandas da Licenciatura em Matemática, ingressas em 2012, moradoras em comunidades campesinas. Escolhemos os TCCs como instrumento de coletas de dados por entendermos que evidenciam as reflexões das licenciandas sobre a experiência de pesquisar na comunidade e se trata de um texto acadêmico reflexivo sobre o observado. $\mathrm{Na}$ apresentação da informação deste método de recolha de dados selecionamos e apresentamos extratos dos registos escritos das licenciandas sobre os saberes, a cultura e a matemática da comunidade na qual estão inseridas. Os fragmentos indiciam também a influência que o curso exerceu nos processos identitários dessas licenciandas como futuras educadoras do campo.

A informação recolhida é analisada e apresentada segundo as seguintes categorias, que foram estabelecidas de acordo com as diretrizes da formação do professor para as escolas do campo, apresentadas ao longo do texto: (i) (Re)conhecendo a Comunidade (o contato com a comunidade e a valorização da cultura); (ii) (Re)conhecendo os sujeitos do campo como produtores de saberes matemáticos (as culturas matemáticas presentes nas práticas cotidianas); e (iii) A experiência do curso: momentos de formação de uma identidade (o reconhecimento e a afirmação de suas identidades de professoras do campo).

\section{Análise de resultados}

Os olhares das licenciandas sobre a realidade da comunidade campesina e os saberes matemáticos produzidos nessa comunidade são organizados a partir das três categorias antes referidas. 


\section{(Re)conhecendo a Comunidade}

Em relação ao contato com a realidade da comunidade, as licenciadas evidenciam que a sua formação lhes possibilitou a percepção e a valorização da cultura local e a identificação como sujeitas nas lutas e construções dos povos campesinos.

Esse trabalho deu-nos a oportunidade de aproximarmos de maneia clara e reflexiva da realidade camponesa da minha comunidade e assim entender alguns dos saberes dessa comunidade e as valorizando como educadora e como sujeito do campo. (Ferreira_TCC)

Tendo em vista que essas práticas fazem parte da cultura da comunidade (...). Nesse trabalho pude entender a importância de desenvolver um trabalho que apresente práticas culturais que perpassaram gerações e que são próprias da comunidade. (Pereira_TCC)

As licenciandas expressam uma postura reflexiva ao evidenciarem a importância de atenderem práticas culturais que perduram ao longo do tempo, o que remete para a valorização dos saberes da comunidade em que se inserem e da integração desses saberes e das questões que envolve o campesinato na escola do campo.

Olhar para a singularidade dos alunos do campo, fica nítido que a Educação Matemática desenvolvida nessas escolas precisa de outra proposta metodológica e curricular. (Ferreira_TCC)

Não percebia que as práticas podem se relacionar com algum tipo de conhecimento matemático, que tinha visto na escola. Ao ingressar no curso o LeCampo e ter contato com algumas disciplinas da área e discussões teóricas, (...) comecei a perceber a matemática em muitas práticas que aconteciam na minha comunidade. (Pereira_TCC)

O trabalho desenvolvido no TCC promoveu a apropriação do discurso e das diretrizes da proposta do curso de Formação de Educadores do Campo no sentido de uma crítica ao ensino da Matemática nas escolas do campo e da realidade atual dessas mesmas escolas conforme nos indica o trecho seguinte explictado por Pereira: "não percebia que as práticas da comunidade poderiam estar relacionadas com algum tipo de conhecimento matemático, que tinha visto na escola". Trata-se de uma perspetiva crítica do ensino de matemática nas escolas do campo, o que é corroborado por Ferreira quando indica que a matemática desenvolvida nas escolas do campo "precisa de outra proposta metodológica e curricular". Inferimos que as licenciandas advogam um ensino para além da memorização de regras ou de estratégias de resolução de problemas centrados em conteúdos pouco significativos para os estudantes do campo, o que não contribui para uma boa formação matemática dos sujeitos campesinos. 


\section{(Re)conhecendo os sujeitos do campo como produtores de saberes matemáticos}

As licenciandas reconhecem as culturas matemáticas presentes nas práticas cotidianas dos moradores da comunidade e trazem exemplos dessa matemática produzida em momentos do trabalho.

Os sujeitos constroem ideias matemáticas surgidas das necessidades de sobrevivências do grupo. (...) Nas observações feitas, percebi a existência da mobilização de saberes e fazeres envolvendo conhecimentos matemáticos pelos sujeitos durante a produção e venda da farinha de mandioca. (Pereira_TCC)

Apesar deles terem pouca escolarização, não utilizar unidades do sistema internacional de medidas (SI), a não ser a medida do litro, e padrões da matemática acadêmica aquela família possuía e utilizava diversos conhecimentos matemáticos capazes de quantificar e mensurar seus produtos e sua produção. (Ferreira_TCC)

O reconhecimento de saberes matemáticos latentes na comunidade destaca o papel que esses saberes podem ter na aprendizagem dos alunos das comunidades campesinas. Na mera consecução de produtos de consumo da própria família e de comercialização as licenciandas percebem a importância do conhecimento que adquirem na observação das práticas culturais dos campesinos para a contextualização dos conteúdos que são abordados nas aulas das Escola do Campo. Trata-se de um conhecimento situado que se desenvolve no diálogo com a realidade em que se inserem, como também exemplificam as seguintes situações:

Nessa matemática pude perceber também que o uso da proporção, por
exemplo: se uma quarta são 6 pratos ou 18 litros, duas quartas são 12
pratos ou 36 litros e assim sucessivamente. Também há a prática da
contagem ao medir um saco, contam de prato em prato até completar
o saco. (Pereira_TCC)
Um alqueire equivale a aproximadamente a um saco de 50 quilos.
Com uma samba ou um carrinho de mandioca, obtém-se uma quarta
de farinha. Na região, essa quarta equivale a aproximadamente a um
"tambor" de 12 quilos e 500 gramas. Um tambor equivale a
aproximadamente 10 medidas. Uma medida equivale
aproximadamente a um 1 quilo e quatrocentas gramas.
(Ferreira_TCC)

A valorização do conhecimento da cultura campesina emerge da observação de como os campesinos usam proporções, estratégias de contagem e de comparação, medidas de áreas, estabelecem correspondências entre medidas de àrea e de volume e como estabelecem relações entre a parte e o todo. Contudo, não se percebe da apropriação desses conhecimentos em exemplos que poderiam ser apresentados em sala de aula e como seriam considerados no conteúdo programático da disciplina e do currículo escolar. 


\section{A experiência do curso: momentos de formação de uma identidade}

$\mathrm{Na}$ formação das licenciandas muito contribuiram as atividades e os estudos realizados no decorrer do curso na sua formação de Educadoras do Campo, o que indiciam que lhes possibilitou fortalecer as suas identidades campesinas e a percepção das lutas campesinas pela conquista de direitos.

Nasci no campo, saí do campo, mas nunca neguei o campo, me qualifiquei para atuar como educadora do campo. Meus vínculos com o campo e minha formação acadêmica me torna uma educadora de matemática do campo. (Ferreira_TCC)

Ao frequentar o curso a minha mente se abriu para novos conhecimentos. A riqueza de conhecer tantas realidades do campo em um mesmo espaço fez aflorar em mim o desejo de mostrar e defender a realidade da minha comunidade e a sua cultura como professora e campesina. Lutar pela dignidade de nosso povo. (Pereira_TCC)

Nas suas perspetivas emerge o movimento de (re)construção e ampliação de olhares para a comunidade e seus contextos culturais, sociais e da 'vida campesina', o que permitem inferir que caminharam na direção de (re)conhecerem o lugar da matemática na cultura e na escola do campo e de se (re)conhecerem como educadoras e sujeitas do campo. Como destaca Molina (2009), "a valorização e o reconhecimento da identidade dos povos do campo é uma questão fundamental para a realização de uma educação do campo" (p. 32).

\section{Conclusão}

Um dos grandes desafios da Educação do Campo está na tarefa de criar a sua pedagogia para ligar o trabalho educativo da escola local à realidade concreta do campo, com a atividade real dos camponeses e das camponesas de forma a reconhecê-los como produtores de alimento e na preservação dos territórios e das nascentes de água, da terra, dos saberes e da vida produtiva e cultural do campo. Trata-se de um desafio de enteder que a Educação do Campo sem um sentido social e cultural perde a sua vitalidade (MOLINA, 2011). Ligado a esse desafio está a formação de professores que consigam, como destacam as licenciandas Pereira e Ferreira, comungar suas práticas docentes à suas práticas de cidadã e à sua identidade camponesa.

Consideramos fundamental que as Licenciaturas em Educação do Campo propiciem momentos de imersão na realidade, atividades de natureza investigativa, questionadora das relações sociais, culturais e do trabalho, com o sentido dos licenciandos perceberem que não é natural achar que os campesinos não produzem saberes. Assim, como indiciam Pereira e Ferreira, a formação inicial de professores do campo tem de pensar a prática docente também na dimensão daquilo que a condiciona e dá sentido, pensar essa prática tendo como foco o que 
a implica na vida da comunidade. Para tanto, entendemos a prática, na concepção ampliada de Wenger (2001), como tempo comunidade que permite estabelecer relações entre o modo como os licenciandos vivenciam o mundo e se relacionam com ele e a produção de sentidos e significados do modo como agem e leem a realidade. As licenciandas em matemática levamnos a defender a conservação e aprimoramento da proposta de uma prática docente conectada e direcionada também à reflexão crítica da realidade no processo de desenvolvimento da identidade de professores do campo. Sabendo que essa postura é uma construção, não se encerra na formação inicial mas que tem a sua sustentação básica nesse momento da formação.

Apesar do muito que ainda há para construir em relação à formação do educador do campo, o curso em análise acerta na sua proposta de formação inicial de professores do campo, na área da matemática, em lidar com as realidades possíveis onde a educação do campo acontece. Assim, o curso não perpetua o olhar hegemônico para a sala de aula de matemática, para o conteúdo a ser ensinado e, principalmente, para os sujeitos - crianças, jovens e adultos - destinatários da educação escolar alvo de críticas nas demais licenciaturas.

Temos consciência da continuidade dessse estudo, focando as ações educativas dos licenciandos no sentido de perceber como se têm realizado, pois é necessário ter clareza do contexto que cada professor atua, evitando cair na armadilha de formar "um professor idealizado, despido de suas particularidades geográficas, sociológicas, políticas, econômicas, pessoais" (GARNICA, 2008, p. 3)

Concluindo, as formandas evidenciam a importância da formação do professor que atende a especificidades do campo e que se encontrem comprometidos com a realização plena dos sujeitos das escolas como cidadãos. Percebe-se que as vivências proporcionadas ao longo do curso possibilitaram um olhar investigativo e reflexivo para o cotidiano da comunidade na qual vivem, o que lhes proporcionou outra dimensão de seus lugares como educadoras do campo. A formação de Educadoras do Campo, na área de conhecimento da matemática no LeCampo, contribuiu para o reconhecimento de pertencimento ao universo campesino e a afirmação de identidades de professoras de matemática do campo.

\section{Referências bibliográficas}

ALARCÃO, I. (1996). Reflexão critica sobre o pensamento de D. Schön e os programas de formação de professores. In.: I. ALARCÃO (Org.), Formação reflexiva de Professores: Estratégias de Supervisão (pp. 9-39). Porto: Porto Editora.

ALARCÃO, I. (1996). Ser professor reflexivo. In.: I. ALARCÃO (Org.), Formação reflexiva de Professores: Estratégias de Supervisão (pp. 171-189). Porto: Porto Editora. 
AMARAL, M. J., MOREIRA, M. A. \& RIBEIRO, D. (1996). O papel do supervisor no desenvolvimento do professor reflexivo: estratégias de supervisão . In.: I. ALARCÃO (Org.), Formação reflexiva de Professores: Estratégias de Supervisão (pp. 89-119). Porto: Porto Editora.

ANDRÉ, M., \& AFONSO, E. D. (2000). Etnografia da prática escolas. Campinas: Papirus Editora.

ARROYO, M. G. (2007). Políticas de formação de educadores(as) do campo. Caderno Cedes, 27(72), 157-176.

ARROYO, M. G. (2008). Oficio de Mestre: imagem e auto-imagens. Petrópolis, RJ: Vozes.

AUAREK, W. A \& SILVA, P. S. (2017). Impacto do Curso de Especialização na prática pedagógica dos formadores em Ciências da Natureza e da Matemática. In: M. C. MOLINA, (Org.), Licenciaturas em Educação do Campo e o ensino de Ciências Naturais: Volume II, Brasilia, Edtora UNB. 239-256p

D’AMBROSIO, U. (1990). Etnomatemática. São Paulo: Editora Ática.

D’AMBROSIO, U. (2005). Etnomatemática: Elo entre as tradições e a modernidade. Belo Horizonte: Editora Autêntica.

FANFANI, E. T. (2007). Consideraciones sociológicas sobre profesionalização docente. Educação e Sociedade, 99(28), 335-353.

FERNANDES, B. M. (2006). Os campos da pesquisa em Educação do Campo: espaço e território como categorias essenciais. In: M. C. MOLINA, (Org.), Educação do Campo e Pesquisa: questões para reflexão (pp. 27-39). Brasília: Ministério do Desenvolvimento Agrário.

FIORENTINI, D. (2008). A pesquisa e a prática de formação de professores de Matemática em face das políticas públicas no Brasil. Bolema, 21(29), 43-70.

FIORENTINI, D. \& OLIVEIRA, A. T. C. C. (2013). O lugar das Matemáticas na licenciatura em Matemática: que matemáticas e que práticas formativas. Bolema, 27(47), 917-938.

FREIRE, P. (2011). Pedagogia da Autonomia. Rio de Janeiro: Paz e Terra.

FREIRE, P. (1981). Pedagogia do Oprimido. Rio de Janeiro: Paz e Terra.

GARCIA, C. M. (1999). Formação de Professores para a mudança educativa. Porto: Porto Editora.

GARNICA, A. V. M. (2008). Um ensaio sobre as concepções de professores de Matemática: possibilidades metodológicas e um exercício de pesquisa. Educação e Pesquisa, 34(3), 495-510.

KNIJNIK, G. (2001). Educação matemática, exclusão social e política do conhecimento. Bolema, $16(14), 12-28$.

LOPES, S. (2016). A prática pedagógica na educação do campo com foco na formação profissional. Acedido em 10 de setembro, 2016, de www.educonse.com.br/xcoloquio.

MOLINA, M. C. (2014). Análises de Práticas contra-hegemônicas na formação de Educadores: reflexões a partir do Curso de Licenciatura em Educação do Campo. In: J. V. SOUZA et al. (Orgs.), $O$ método dialético na pesquisa em educação. Editora Autores Associados (pp. 263-290), Campinas, SP.

MOLINA, M. C. (2011). Desafios teóricos e práticos na execução das políticas pública de Educação do Campo. In: A. MUNARIM, S. BELTRAME, S. F. CONTE \& Z. I. PEIXER (Orgs.), Educação do Campo: reflexões e perspectivas (pp. 103-121). Florianópolis: Insular. 
MOLINA, M. C. (2009). Possibilidades e limites de transformações das escolas do campo: reflexões suscitadas pela Licenciatura em Educação do Campo - UFMG. (Coleção Caminhos da Educação do Campo; 1) In: M. I. ANTUNES-ROCHA \& A. A. MARTINS (Org.), Educação do Campo: desafios para a formação de professores. Belo Horizonte: Autêntica Editora.

PIMENTA, S. G. \& LIMA, M. S. L. (2006). Estágio e docência: diferentes concepções. Revista Poieis, 3(4), 5-24.

PIMENTA, S. G. (Org.) (2005). Saberes pedagógicos e atividade docente. São Paulo: Cortez.

PONTE, J. P. (1994). O desenvolvimento profissional do professor de Matemática. Educação e Matemática, 31, 9-12 e 20.

SCHÖN, D. (1992). Formar professores como profissionais reflexivos. In: A. NÓVOA (Coord.), Os professores e a sua Formação (pp. 77-91). Lisboa: Dom Quixote.

VISEU, F. (2009). A formação do professor de Matemática, apoiado por um dispositivo de intervenção virtual no estágio pedagógico. Braga: CIEd, Universidade do Minho.

ZEICHNER, K. M. (1993). A formação reflexiva de professores: Idéias e práticas. Lisboa: Educa.

WENGER, E. (2001). Comunidades de práctica: aprendizaje, significado y identidad. Barcelona: Ediciones Paidós Ibérica. 